\title{
Fractional excretion of sodium and fractional excretion of urea in differentiating prerenal from renal azotemia complicating circulatory shock
}

\author{
HM Sherif*, AR Yassin, AY Mousa, A Esmat \\ From ESICM LIVES 2015 \\ Berlin, Germany. 3-7 October 2015
}

\section{Background}

Fractional excretion of sodium (FENa) is used to differentiate renal from prerenal azotemia. However, many drugs and medical problems affect the sodium $\left(\mathrm{Na}^{+}\right)$ handling in the kidney. On the other hand, the fractional excretion of urea (FEurea) is mainly dependent on passive forces so that it is less influenced by the diuretic therapy.

\section{Objective}

Comparison between FENa and FEurea in differentiating renal from prerenal azotemia complicating circulatory shock, and the effect of diuretics on their handling.

\section{Methods}

Both serum FENa \& FEurea were measured in 40 patients (pts) with acute kidney injury (AKI) complicating circulatory shock during their stay in ICU. All patients were divided into 26 pts (mean: $60.0 \pm 15.15$ years) with prerenal azotemia (group-1) and 14 pts (mean: $56.29 \pm 19.5$ years) with renal azotemia (group-2). Group-1 was subdivided into 12 pts (group-1a) who didn't receive diuretics 24 hours before the sampling process and 14 pts (group-1b) who received diuretics during their stay in ICU. Acute kidney injury was diagnosed according to the RIFLE-criteria (Risk, Injury, Failure, Loss and End-stage Kidney) in oliguric patients.

\section{Results}

Both FENa and EFurea showed significantly increased incremental values with higher RIFLE-criteria from mild to severe AKI. Compared to pts of group-2, pts of group-1 showed significantly lower FENa $(0.99 \pm 0.66$ and $2.57 \pm 1.73, \mathrm{P}<0.05)$, and significantly lower FEurea $(29.7 \pm 7.6$ and $43.7 \pm 15.4, P<0.001)$, respectively. For differentiating renal from prerenal azotemia; compared to FENa, FEurea showed better sensitivity $(78.1 \%$ vs. $71.4 \%)$ and specificity ( $88.5 \%$ vs. $69.4 \%)$ respectively. Moreover, compared to pts of group-1a with those of group-1b, FEurea were not significantly affected by the use of diuretics; sensitivity ( $78 \%$ vs. $78 \%$ ) and specificity ( $92 \%$ vs. $88 \%$ ), respectively. As a predictor of differentiation, the cutoff value of FEurea was $34.12 \%$ $(P<0.001)$ and the cutoff value of FENa was $1.1 \%$ $(P<0.05)$.

\section{Conclusions}

FEurea is more sensitive, specific and less affected by the use of diuretics than FENa in differentiating renal from prerenal azotemia in patients with AKI complicating circulatory shock.

Published: 1 October 2015

\section{doi:10.1186/2197-425X-3-S1-A262}

Cite this article as: Sherif et al:: Fractional excretion of sodium and fractional excretion of urea in differentiating prerenal from renal azotemia complicating circulatory shock. Intensive Care Medicine Experimental 2015 3(Suppl 1):A262. 